\title{
Where do children study? Behavioral observations
}

\author{
JAMES E. PATTON \\ Grant Wood Area Education Agency, Cedar Rapids, Iowa \\ DONALD K. ROUTH \\ University of Miami, Coral Gables, Florida
}

and

THOMAS A. STINARD

Arthur Andersen and Company, Chicago, Illinois

\begin{abstract}
The study conditions preferred by elementary and junior high school students for two different types of schoolwork were examined. Thirty-three students in Grades 5, 6, 8, and 9 were observed individually in a private study area at school where they worked on classroom mathematics and reading assignments (in counterbalanced sequence) under conditions of their own choosing. For both types of schoolwork, a majority of the students chose to study with radio or television operating. This preference was more pronounced for mathematics work than for reading. The results confirmed the findings of previously reported survey data. Individual students' self-reports were significantly correlated with their observed preferences.
\end{abstract}

In a previous study, Patton, Stinard, and Routh (1983) asked 387 students in Grades 5 through 9 to describe their usual home study conditions for different types of schoolwork. It was found that a majority of students at each grade level (including high achievers) reported that they preferred to study under noisy circumstances (i.e., with a radio, stereo, or television set in operation). The selection of these seemingly distracting home study conditions was neither wholesale nor indiscriminate. Rather, there were reliable differences in the preferred study conditions for different tasks (i.e., mathematics work generally was done under noisy conditions, whereas quieter conditions were preferred for reading assignments).

The present study was designed to assess the validity of the above survey data by direct observations of children's study behavior. Based on the previous findings, the expectations were (1) that students would most often select noisy study conditions, and (2) that there would be differences between study conditions selected for reading and mathematics assignments. In a second part of the study, the same subjects were administered a modified version of the home study survey used by Patton et al. (1983). It was anticipated that these self-report data would replicate the previous findings and that the self-reports would be significantly correlated with the study behavior actually observed.

Requests for reprints should be sent to James E. Patton, Grant Wood Area Education Agency, 4401 6th Street, S.W., Cedar Rapids, IA 52404.

\section{METHOD}

\section{Subjects}

Thirty-three public school students ranging in age from 10 years, 7 months to 16 years, 1 month served as subjects. Twelve were in elementary school (Grades 5 and 6), and the other 21 were in junior high school (Grades 8 and 9). The sample included 14 males and 19 females. The students were in the average range of intellectual ability and academic achievement in reading and mathematics, as indicated by scores on the Cognitive Abilities Test and the Iowa Test of Basic Skills, respectively.

\section{Setting}

The room at school where the students were observed contained a school desk, large table, straight-backed desk chair, lounge chair, large beanbag chair, floor cushion, and rug. A mobile cart in the room contained a 19-in. television set, an AM-FM radio, and a portable AMFM radio with earphones. The experimenter could unobtrusively watch the students through an aperture in a partition within the room.

\section{Procedure}

Because of the children's school schedules, it was possible for elementary students to participate only in the afternoons and the junior high students only in the mornings. Students were requested to bring along two regular schoolwork assignments, one involving mathematics and the other reading. The students were asked to work on (but not necessarily complete) each of these assignments under self-selected study conditions, in randomly assigned, counterbalanced sequence. The experimenter noted the study conditions selected by the students in each session and kept track of the time spent in the two sessions.

After the two study sessions were completed, the student was given time for a short break. Then the student was brought back and asked a series of questions about home study patterns adapted from the Patton et al. (1983) study so as to be consistent with the study condition options just observed. For each course subject, responses to questions about days per week and time per day were multiplied to estimate time per week spent on that kind of homework. 


\section{RESULTS}

For the reading task, 12 of the students were observed to study under quiet conditions, 17 with the radio on, and 4 with the television on. For the mathematics task, 4 students studied under quiet conditions, 21 with the radio on, and 8 with the television on. Following the rationale of Patton, Routh, and Offenbach (1982), an observed preference for quiet was scored as 0 , preference for radio on as +1 , and preference for television on as +2 . Students were observed to prefer higher levels of extratask stimulation for doing their mathematics (mean score = $1.12, S D=.60$ ) than for doing their reading (mean $=$ $.76, S D=.67)$. This difference between the scores for mathematics and the scores for the reading assignment was assessed by means of a paired $t$ test, which was significant $[t(32)=3.00, p<.01]$. There were no significant sex differences in these scores. There was a modest, but significant, correlation between the students' observed stimulation preference scores for reading and mathematics $[r(31)=.39, p<.05]$. Students who spent more time on their reading assignments tended to be those who were observed to prefer higher levels of extratask stimulation $[r(31)=.38, p<.05]$. Students with higher verbal IQ scores on the Cognitive Abilities Test were observed to prefer significantly higher levels of extratask stimulation $[r(31)=.36, p<.05]$. Other than these correlations, none of the other relationships between extratask stimulation preferences and individual difference variables (age, intellectual ability, achievement) were statistically significant.

In response to the questions about home study patterns, students reported a mean total time of $2.60 \mathrm{~h}$ per week spent studying. Approximately two thirds of the total reported study time (mean $=1.74 \mathrm{~h}$ ) was spent on mathematics assignments, while the mean time devoted to social sciences, science, and reading or language arts assignments was $.58, .13$, and $.15 \mathrm{~h}$ per week, respectively. For homework involving reading, 14 students reported that they preferred quiet home study conditions, 15 that they liked the radio on, and 4 that they liked the television on while reading. For homework involving mathematics, 2 reported preferring quiet home study conditions, 16 preferred the radio on, and 15 preferred the television on. The mean preference scores were 1.39 for mathematics $(S D=.61)$ and .70 for reading $(S D=.68)$. The difference between the two was significant by paired $t$ test $[t(32)=5.00, p<.01]$. The correlations between observed and reported stimulation preferences were significant, both for reading $[r(31)=.63, p<.01]$ and for mathematics $[r(31)=.73, p<.01]$. The correlations between reported extratask stimulation preferences and age, IQ, and achievement were all nonsignificant.

\section{DISCUSSION}

The present research took a second step into a line of investigation concerned with how children perceive and behave toward distractors in study environments. Its goal was to replicate and extend the home study survey results of Patton et al. (1983). Like the previous study, this research clearly demonstrated that students preferred to study in the presence of distractors. In fact, 50 of the 66 assignments students brought to the private study area at school were studied either with the radio or the television set on, and this behavior was matched closely by self-descriptions of home study conditions given by the same students.

On the other hand, the present results also indicate that students do not simply select their study conditions in a haphazard manner. In agreement with the previous survey data, the students in this study adjusted their study conditions to include higher levels of extraneous stimulation to go with mathematics work and lower levels to go with reading assignments.

One hypothesis concerning the findings of this research is that, although extratask stimulation may have a short-term ill effect on information processing in the academic task, its long-term net effect may be beneficial because it helps the student avoid boredom and therefore stay "on task" for a longer time. Indeed, in the present study, students who chose a higher level of stimulation stayed at their reading task longer than those who chose a quiet environment. Future research needs to follow up this intriguing finding.

\section{REFERENCES}

Patton, J. E., Routh, D. K., \& Offenbach, S. I. (1981). Televised classroom events as distractors for reading-disabled children. Journal of Abnormal Child Psychology, 9, 355-370.

Patton, J. E., Stinard, T. A., \& Routh, D. K. (1983). Where do children study? Journal of Educational Research, 76, 280-286.

(Manuscript received for publication May 17, 1986.) 